
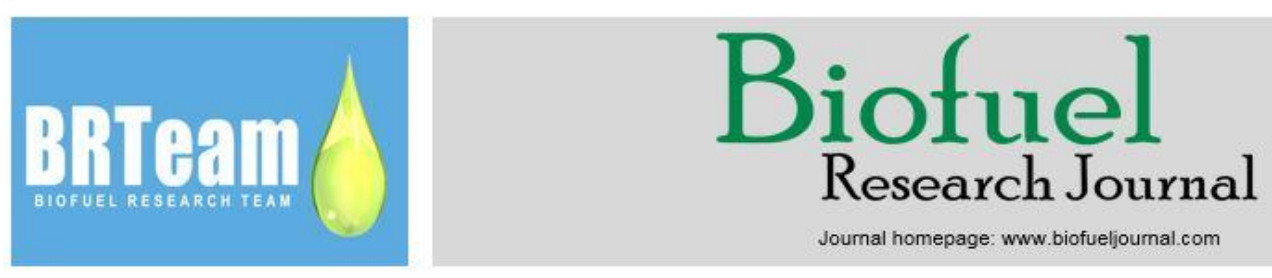

Review Paper

\title{
Recent trends in acetone, butanol, and ethanol (ABE) production
}

\section{Keikhosro Karimi $^{1,2, *}$, Meisam Tabatabaei ${ }^{3,4}$, Ilona Sárvári Horváth ${ }^{5}$, Rajeev Kumar $^{6}$}

${ }^{1}$ Department of Chemical Engineering, Isfahan University of Technology, Isfahan 84156-83111, Iran.

${ }^{2}$ Industrial Biotechnology Group, Institute of Biotechnology and Bioengineering, Isfahan University of Technology, Isfahan 84156-83111, Iran.

${ }^{3}$ Microbial Biotechnology Department, Agricultural Biotechnology Research Institute of Iran (ABRII), AREEO, Karaj, Iran.

${ }^{4}$ Biofuel Research Team (BRTeam), Karaj, Iran.

${ }^{5}$ Swedish Centre for Resource Recovery, University of Borås, 50190 Borås, Sweden.

${ }^{6}$ Center for Environmental Research and Technology (CE-CERT), Bourns College of Engineering, University of California, Riverside, California, USA.

\section{HIGHLIGHTS}

$>$ Biobutanol is an advantageous competitor to most biofuels and petroleum-based fuels.

$>$ Suitable substrates and low concentration of products are among the process challenges.

$>$ In spite of different challenges, lignocelluloses are among the most suitable feedstocks.

$>$ To revamp the old $\mathrm{ABE}$ or ethanol plants to butanol, more researcs in different disciplines are necessary.

$>$ This review paper discusses the basic and applied perspective of the process.

\section{GRAPHICAL ABSTRACT}

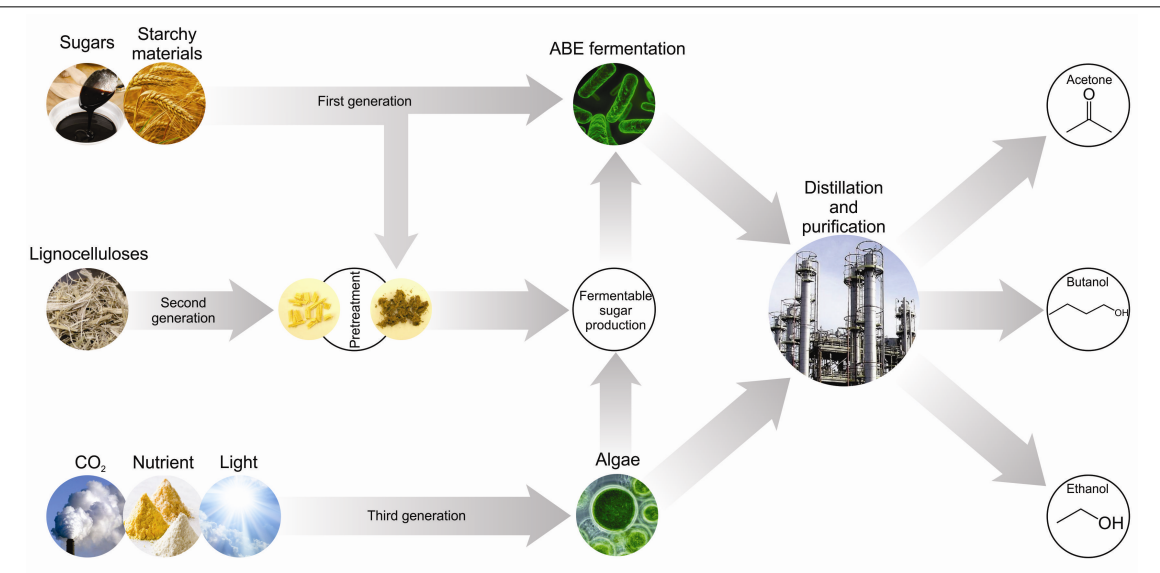

\section{ARTICLE INFO}

\section{Article history:}

Received 12 September 2015

Received in revised form 1 October 2015

Accepted 11 October 2015

Available online 1 December 2015

\section{Keywords:}

Acetone, butanol, and ethanol (ABE)

Fermentation

Recent trends

\begin{abstract}
Among the renewable fuels considered as a suitable substitute to petroleum-based gasoline, butanol has attracted a great deal of attention due to its unique properties. Acetone, butanol, and ethanol (ABE) can be produced biologically from different substrates, including sugars, starch, lignocelluloses, and algae. This process was among the very first biofuel production processes which was commercialized during the First World War. The present review paper discusses the different aspects of the ABE process and the recent progresses made. Moreover, the microorganisms and the biochemistry of the ABE fermentation as well as the feedstocks used are reviewed. Finally, the challenges faced such as low products concentration and products` inhibitory effects on the fermentation are explained and different possible solutions are presented and reviewed.
\end{abstract}

* Corresponding author at: Tel.: +983113915623

E-mail address: karimi@cc.iut.ac.ir

Please cite this article as: Karimi K., Tabatabaei M., Sárvári Horváth I., Kumar R. Recent trends in acetone, butanol, and ethanol (ABE) production. Biofuel Research Journal 8 (2015) 301-308. DOI: 10.18331/BRJ2015.2.4.4 


\section{Contents}

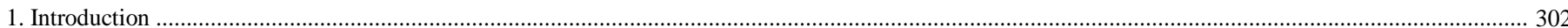

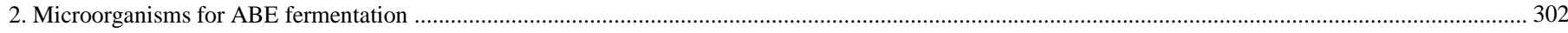

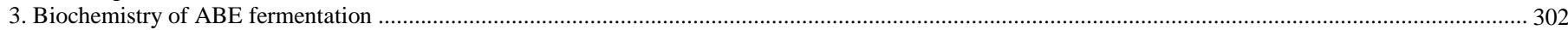

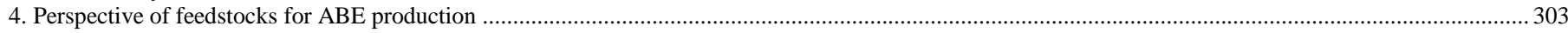

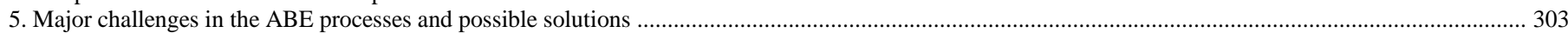

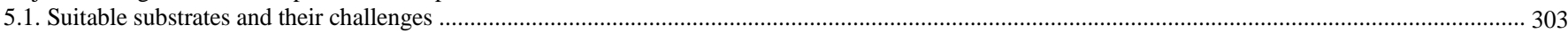

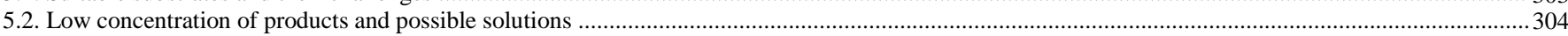

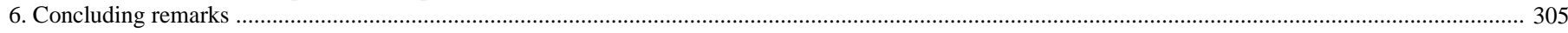

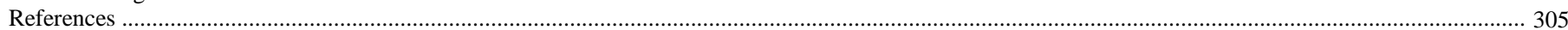

\section{Introduction}

Among the renewable fuels, butanol is considered as a competitor to petroleum-based products. Butanol, compared to ethanol, has attracted more attention due to its unique properties (Durre, 2007; Ni and Sun, 2009; Patakova et al., 2013; Tigunova et al., 2013; Karimi and Pandey, 2014; Li et al., 2014). A mixture of acetone, butanol, and ethanol (ABE) can be produced biologically from different sugars and starches. This process was commercialized in the Union of Soviet Socialist Republics, England, Canada, and the USA during the First World War. Several industrial units were also established in other countries including Japan, Australia, China, and South Africa (Linden et al., 1986; García et al., 2011; Köpke and Dürre, 2011; Dong et al., 2012). Initially, ABE fermentation was mainly being used for production of acetone as a solvent for military applications. However, nowadays there is more interest in butanol to be used as a liquid renewable fuel (Awang et al., 1988; Maddox, 1989; Durre, 2007).

Butanol, $\mathrm{C}_{4} \mathrm{H}_{9} \mathrm{OH}$, is a colorless liquid among the four-carbon alcohols. It can be produced by chemical and biological methods. The economy of butanol production by chemical methods highly depends on oil price while by biological methods, the cost of the raw material used is the determining factor (Linden et al., 1986). Nowadays, due to the increasing price of crude oil, biological processes of butanol production have attracted significant attentions (Amiri et al., 2015). Biobutanol, compared to ethanol, has several advantages. One of the most important advantages is that it could be blended with gasoline at any percentages. Furthermore, butanol has a lower vapor pressure and absorbs less moisture, and is less corrosive; thus, its transportation is more convenient. Butanol has higher energy content than ethanol and is more similar to diesel fuels, in terms of energy content (Awang et al., 1988; Maddox, 1989; Dong et al., 2012; Tigunova et al., 2013). Different processes including batch, fed-batch, and continuous fermentation with and without in situ product removal with native and modified strains in the free and immobilized cells are currently applied (Bankar et al., 2012; Setlhaku et al., 2012; Survase et al., 2012; Xue et al., 2012; Chen et al., 2013; Ezeji et al., 2013; Jang et al., 2013; Millat et al., 2013; Chen et al., 2014; Rathore et al., 2015), and a number of review and book chapters have been published on this subject (Linden et al., 1986; Maddox, 1989; Durre, 2007; Kharkwal et al., 2009; Ni and Sun, 2009; Gu et al., 2010; García et al., 2011; Dong et al., 2012; Patakova et al., 2013; Tigunova et al., 2013; Li et al., 2014). This review presents an introduction to the process and discusses the challenges and possible solutions for the $\mathrm{ABE}$ production.

\section{Microorganisms for $\mathrm{ABE}$ fermentation}

Certain species of microorganisms are used in biological ABE production process. The most important of these microorganisms is Clostridium genus that includes a variety of butanol-producing bacteria. Some of these bacteria are C. acetobutylicum, C. beijerinckii, C. saccharoacetobutylicum, $C$. aurantibutyricum, and C. sporogenes. (Kharkwal et al., 2009; Ni and Sun, 2009; Patakova et al., 2013). Among these microorganisms, two species, $\boldsymbol{C}$. beijerinckii and $C$. acetobutylicum are the most promising ones for commercial and laboratory applications with high efficiency (Mo et al., 2015). In fact, native and modified forms of these two strains are the most applied microorganisms in ABE production ( $\mathrm{Ni}$ and Sun, 2009; Komonkiat and Cheirsilp, 2013; Patakova et al., 2013; Li et al., 2014). C. acetobutylicum is a rod-shaped, gram-positive, and obligate anaerobic bacterium that forms spores. This is the first species of microorganisms that has been used in industrial ABE fermentation from starch and sugars (Maddox, 1989; Kharkwal et al., 2009; Ni and Sun, 2009). Clostridium spp. can utilize a wide range of simple sugars (i.e., glucose, galactose, and xylose) and disaccharides (i.e., maltose, sucrose, and lactose) (Loyarkat et al., 2013). Direct conversion of starch without necessity of hydrolysis is among the specific features of these strains (Madihah et al., 2001; Li et al., 2014; Thang and Kobayashi, 2014).

Selecting a category or group of microorganisms for biological production of $\mathrm{ABE}$ depends on many factors, including the type of the initial substrate, the desired production rate, required additional nutrients, and bacteriophages resistance (Kumar and Gayen, 2011). Overproduction of butanol by mutagenesis, evolutionary engineering, and recently genomic studies and transcriptional analysis is the subject of a high number of research activities in this area (Kumar and Gayen, 2011; Cooksley et al., 2012; Li et al., 2013). C. acetobutylicum capable of producing high concentration of butanol (as high as $20 \mathrm{~g} / \mathrm{L}$ ) was obtained by mutation, whereas the concentration of butanol in commercial fermentation is typically $12 \mathrm{~g} / \mathrm{L}$ (Xue et al., 2012; Jiang et al., 2014). However, generally the success in screening by mutagenesis and evolutionary engineering highly depends on chance. One of the recent progresses in this field is based on the evolutionary dynamics and natural selection, referred to as artificial simulation of bio-evolution. Using this method, which is a repetitive evolutionary training, C. acetobutylicum that could tolerate $4 \%$ butanol was obtained (Liu et al., 2013).

\section{Biochemistry of $\mathrm{ABE}$ fermentation}

$\mathrm{ABE}$ production by clostridia species has a complex intracellular pathway. The most important products of the intracellular pathway of clostridia species fall into three main categories: (1) solvents (acetone, butanol, and ethanol), (2) organic acids (lactic acid, acetic acid, and butyric acid), and (3) gases (carbon dioxide and hydrogen) (Zheng et al., 2009; Xue et al., 2013). ABE fermentation process begins by the acidogenic phase within the exponential growth phase (Fig. 1). As indicated in Figure 1, each mole of glucose can be converted to either two moles of acetic acid or one mole of butyric acid via acidogenesis. The production of these acids reduces $\mathrm{pH}$ in batch cultivation; thus, without a proper $\mathrm{pH}$ control, an inhibition of the metabolic pathway occurs, referred to as acidic stress. The reason behind this acidic stress is the faster production of these acids compared to their consumption by the cells (Kumar and Gayen, 2011; Xue et al., 2013).

The products of acidogenesis are then transferred to solventogenic phase during the spore formation. Acetic acid can be converted to ethanol or acetone, while butyric acid is converted to butanol. Using $C$. acetobutylicum, aceton, butanol, and ethanol are produced in a ratio of 1:6:3, respectively, within the normal pathway. These solvents are toxic to the cells. About $50 \%$ of the cell growth is hindered by concentrations of 11, 51, and $84 \mathrm{~g} / \mathrm{l}$ butanol, ethanol, and acetone, respectively. Thus, butanol is very toxic to the cells. The inhibitory effects of these solvents are known as solvent stress and a high number of studies have been conducted on this issue as well (Linden et al., 1986; Xue et al., 2013). Generally, clostridia are very sensitive to the medium composition and fermentation conditions. Small amounts of oxygen can completely stop 


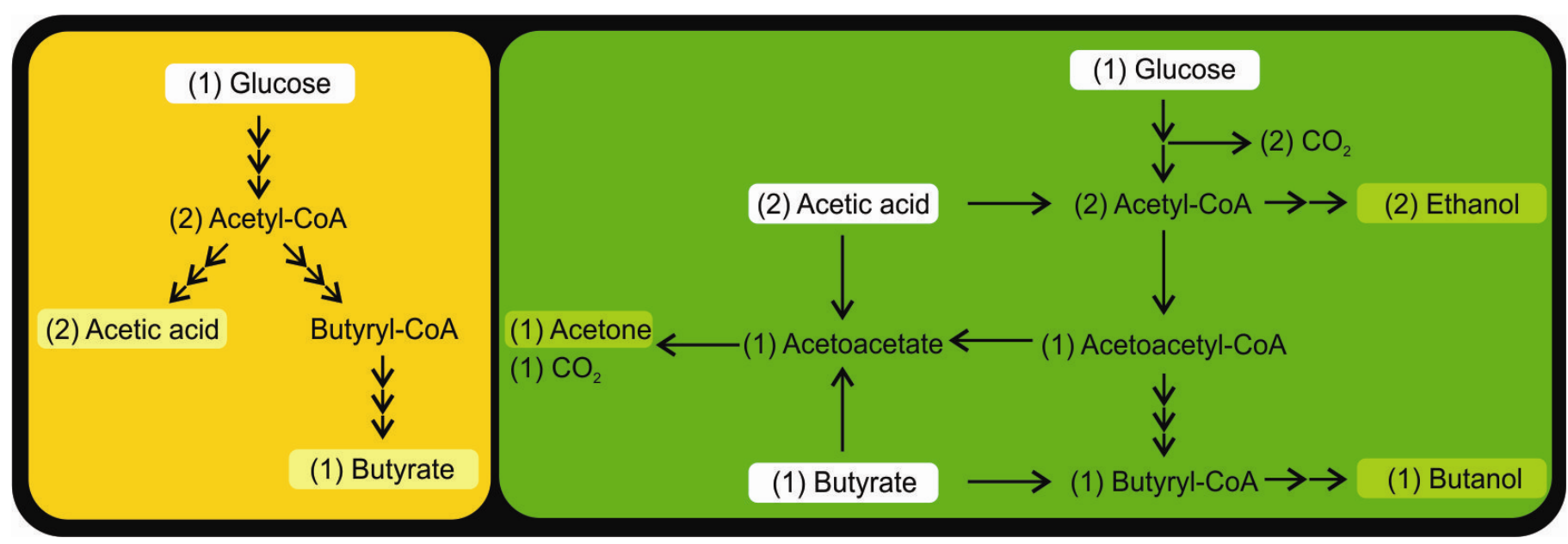

Fig.1. Primary metabolism of C. acetobutylicum. The numbers indicate the moles (Linden et al., 1986; Kumar and Gayen, $201 \mathrm{D}$ ).

the activity of the cells, and some chemicals in minor amounts can affect the product distribution (Choi et al., 2012; Han et al., 2013). For instance, availability of small amount of zinc, e.g., $0.001 \mathrm{~g} / \mathrm{L} \mathrm{ZnSO} 4.7 \mathrm{H}_{2} \mathrm{O}$, can result in earlier shifting to solventogenesis (Wu et al., 2013).

\section{Perspective of feedstocks for ABE production}

The economy of ABE process highly depends on applied feedstocks (Lepiz-Aguilar et al., 2013). Like other first generation biofuels which are derived from sugars and starchy materials, butanol can create the conflict between fuel and food (Sims et al., 2010). Feedstock consumption is more challenging for $\mathrm{ABE}$ compared to ethanol, as production of each ton of butanol needs more than 6 tons of corn, while it is only 3 tons for ethanol production. Thus, recently most of the research activities have been shifted to the second generation butanol which is derived from lignocellulosic biomass such as bagasse, rice straw, wheat straw, grass, and waste woods (Naik et al., 2010). Lignocelluloses are nonfood feedstocks available in large quantity with low cost and seem to be the only promising raw materials for $\mathrm{ABE}$ production at large scale (Kumar et al., 2012). The old ABE processes should be revamped to use lignocelluloses substrates and the currently available ethanol plants can also be reorganized to produce $\mathrm{ABE}$ from lignocelluloses.

The overall process scheme of ABE production from different substrates including lignocelluloses is summarized in Figure 2. However, due to the complex and recalcitrant structure of lignocellulosic materials, they cannot be directly used by microorganisms. Therefore, a processing step, called pretreatment, is required to disrupt the lignocellulosic biomass matrix to make the carbohydrates accessible to enzymes and microorganisms. Then, cellulose and hemicelluloses polymers are hydrolyzed to obtain monomeric sugars (Taherzadeh and Karimi, 2007). Fermentation of sugars is then conducted for production of ABE by microorganisms. Produced ABE is then recovered and purified (Abdehagh et al., 2014). Separation and purification of biobutanol can be conducted during the fermentation (Huang et al., 2014).

\section{Major challenges in the $\mathrm{ABE}$ processes and possible solutions}

Although butanol, as an advanced liquid fuel, has several advantages compared to ethanol, the ABE process has several bottlenecks and challenges hindering its commercial production. Here is a brief introduction to the main challenges and some of their possible solutions.

\subsection{Suitable substrates and their challenges}

$\mathrm{ABE}$ is not a commercially profitable and competitive process without using an inexpensive and widely available substrate (García et al., 2011; Lepiz-Aguilar et al., 2013; Xue et al., 2013; Zhang et al., 2014; Becerra et al., 2015; Kheyrandish et al., 2015). Lignocelluloses are suggested to be suitable substrates becaused sources like municipal solid waste (MSW) and agricultural wastes (namely bagasse and rice straw) are available in huge amounts and mainly useless (Amiri et al., 2010; Hedayatkhah et al., 2013; Shafiei et al., 2013; Amiri et al., 2014; Amiri and Karimi, 2015). However, the main problem is the difficulty to produce fermentable sugar from such substrates, as they have recalcitrant structures and the hydrolytic enzymes are still expensive (Shafiei et al., 2011; Shafiei et al., 2013; Shafiei et al., 2014).

Therefore, the introduction of a pretreatment is needed, which is typically an expensive process step (Shafiei et al., 2010; Sims et al., 2010; Shafiei et al., 2014; Boonsombuti et al., 2015). Hence, investigating suitable pretreatment methods is the focus of a number of current studies and is considered as a key factor for efficient production of $\mathrm{ABE}$ from lignocelluloses. An ideal pretreatment process should efficiently improve the enzymatic hydrolysis, consume lower amounts of chemicals, and produce fewer by-products/inhibitors (Taherzadeh and Karimi, 2008; Karimi et al., 2013). Compared to ethanolic fermenting yeasts, ABE fermenting microorganisms are more sensitive to possible inhibitors present in lignocelluloses hydrolysates, e.g., hydroxymethylfurfural, furfural, and lignin derivatives (Kudahettige-Nilsson et al., 2015). These inhibitors have severe inhibitory effects both on clostridium growth and consequently the ABE production yield (Ezeji et al., 2007; Cai et al., 2013). Therefore, the applied pretreatment should not lead to the production of considerable amounts of inhibitors. For instance, dilute acid pretreatment which produces a high concentration of inhibitors should not be applied, otherwise an extra detoxification process is necessary that also consumes chemicals, and is accompanied with some sugar loss, and production of problematic wastes. Thus, special care should be taken in selection and optimization of the pretreatment processes. Liquid hot water, ammonia, ionic liquid, and organosolv treatments are among the most applied methods (Amiri et al., 2014; Ding et al., 2015), but all these methods have their own drawbacks (Taherzadeh and Karimi, 2008).

On the other hand, the hydrolysate produced through the pretreatment is a very complicated mixture of different components including sugars that cannot be simulated just by pure glucose (Karimi et al., 2005; Taherzadeh and Karimi, 2007; Taherzadeh and Karimi, 2007; Karimi et al., 2013). Lignocelluloses contain both cellulose and hemicellulose and to achieve an economically-feasible ABE production, the latter should not be ignored as it accounts for $14-37 \%$ of the lignocelluloses. If not hydrolyzed and fermented, the hemicellulose fraction ends up as a waste (Karimi et al., 2013). Besides glucose, the hydrolysate of hemicellulose and cellulose contains mainly xylose in the case of agricultural biomass and hardwoods and mannose in the case of softwoods. Other sugars and compounds, e.g., galactose, arabinose, rhamnose, glucuronic acid, methyl glucuronic acid, and galacturonic acid are also present in minor portions (Taherzadeh and Karimi, 2007; Taherzadeh and Karimi, 2008; Taherzadeh and Karimi, 2011; Karimi et al., 2013). Therefore, if al 


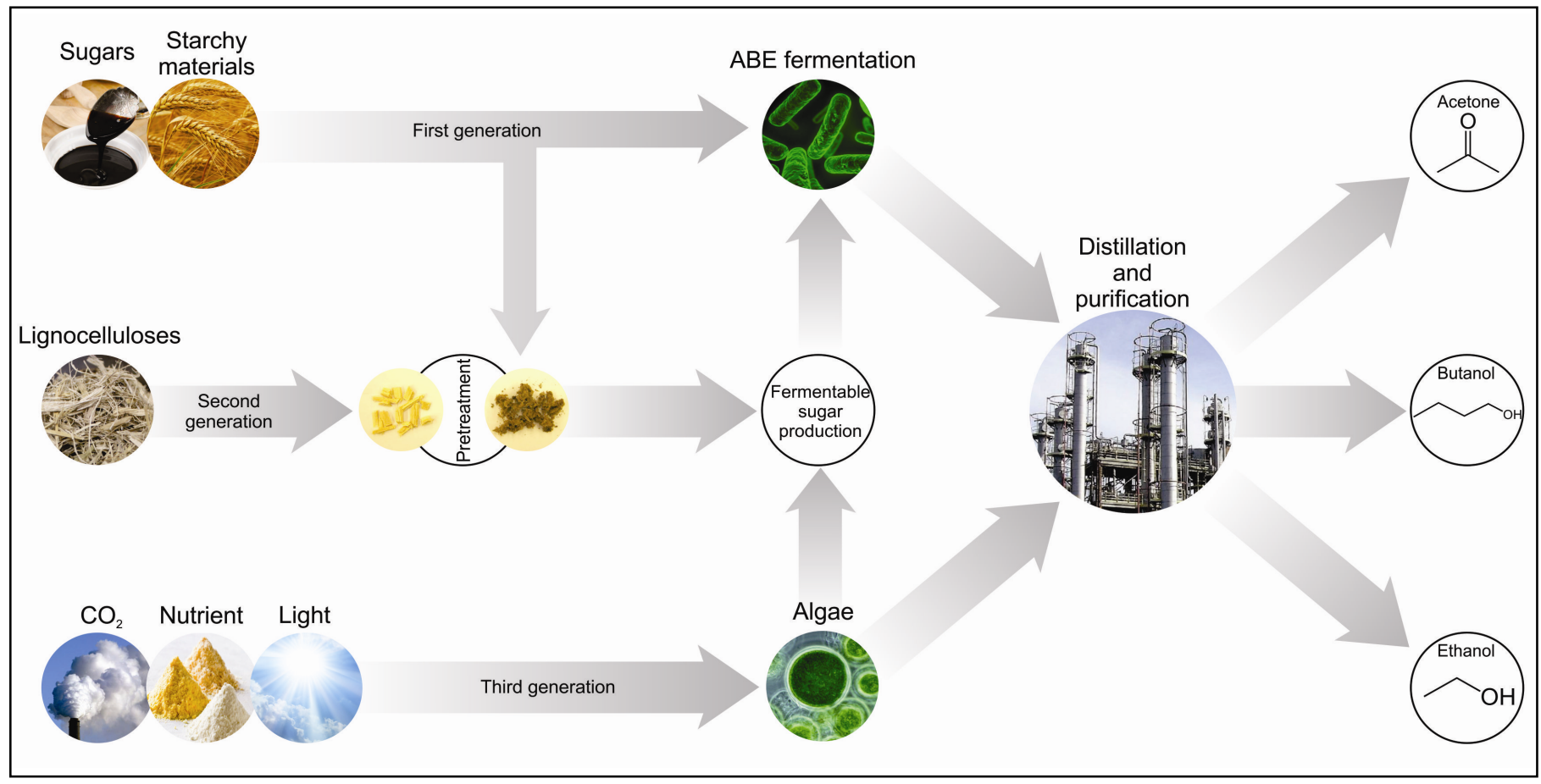

Fig.2. Overall process scheme for acetone, butanol, and ethanol production from lignocellulosic materials.

optimizations are conducted on pure glucose, it does not necessarily give the same results on the hydrolysates. In fact, co-consumption of different sugars takes place in the case of fermentation of hydrolysates to $\mathrm{ABE}$, which is much more complicated than the fermentation of pure glucose. This may also influence the inhibitory effects of the hydrolysate on the bacteria ( $\mathrm{Su}$ et al., 2015).

By applying a suitable pretreatment, the consumption of hydrolytic enzymes can be significantly reduced (Boonsombuti et al., 2015). The price of the hydrolytic enzymes, cellulases, has recently significantly reduced via the global attempts within this area (Karimi et al., 2013). However, cellulases are still much more expensive than the enzymes used for the hydrolysis of starch. Thus, the process for $\mathrm{ABE}$ production should use a minimal amounts of these enzymes to achieve an economically feasible production cycle (Karimi et al., 2013). Plant genetic engineering is also an option to develop plants with less recalcitrant structures. In spite of a number of attempts, it is not possible yet to develop plants with less recalcitrant biomass achieving same yields. Development of plants in which cell wall-degrading enzymes are expressed (Saathoff et al., 2011) as well as changing enzymes involved in lignin biosynthesis (Saathoff et al., 2011), both aiming at the production of easily convertible biomass have also been investigated

Glycerol, an important byproduct of biodiesel industry, has been suggested as a suitable substrate for ABE production (Khanna et al., 2013; $\mathrm{Li}$ et al., 2014; Yadav et al., 2014). Algae are also among the suggested alternative substrates. The algae biomass has several advantages compared to the other substrates (Ellis et al., 2012; van der Wal et al., 2013; Yazdani et al., 2015); however, the production of algae fuels is generally in the early stages of development and a number of serious challenges are still needed to be addressed first. For instance, the biomass of algae is produced in a very dilute solution and its separation and downstream processing are costly. Another option is the direct conversion of solar energy and $\mathrm{CO}_{2}$ to isobutanol by certain algae species (Atsumi et al., 2009; Jang et al., 2012). This strategy is also in its early stage of development and it is not possible to consider yet whether this process would be economically feasible for large scale production.

\subsection{Low concentration of products and possible solutions}

The concentration of ethanol in the commercial scale processes is typically between $5-9 \%$, while it is possible to reach a concentration as high as 16\% (Taherzadeh and Karimi, 2008; Breisha, 2010; Taherzadeh and Karimi, 2011), whereas the concentration of total produced ABE is typically between 2-4\% (Xue et al., 2013; Huang et al., 2014; Ye et al., 2015). Therefore, the cost of separation and purification of ABE is much higher than that of ethanol. This is principally related to toxicity of the produced solvents on the ABE producing bacteria (Awang et al., 1988). The suggested solutions are using more tolerant strains, recovery of the solvents during the fermentation, and using less energy demanding and inexpensive purification processes (García et al., 2011; Xue et al., 2013; Huang et al., 2014; Dhamole et al., 2015). The solvents, especially butanol, are severe inhibitors of the solvent-producing bacteria (Xue et al., 2013). Thus, product removal technologies, also referred to as in situ butanol removal, are suggested and applied in laboratory and pilot scales (Abdehagh et al., 2014; Huang et al., 2014). Pervaporation (Friedl et al., 1991; Jitesh et al., 2000; Cai et al., 2013), liquid-liquid extraction (Yen and Wang, 2013), gas stripping (Ezeji et al., 2004; Xue et al., 2012), vacuum fermentation (Mariano et al., 2012; Qureshi et al., 2014), perstraction (Qureshi and Maddox, 2005), and adsorption (Liu et al., 2014; Thompson et al., 2014) of the solvents are among the most applied techniques. Pervaporation and perstraction are highly selective and efficient; however, the high cost and the possibility for fouling limit their potentials for large scale applications. Among the membrane separation processes, polydimethylsiloxane (PDMS)/ceramic composite membranes have been shown to lead to less fouling problems (Chen et al., 2014). Liquid-liquid extraction is highly selective (Bankar et al., 2012) but the applied solvents are typically toxic to the bacteria; thus, special nontoxic extractants such as biodiesel should be applied (Yen and Wang, 2013). Moreover, after butanol extraction, a distillation/evaporation step is necessary to recover butanol which is an energy demanding process. On the other hand, another method, gas stripping, can be simply applied in 
laboratory, pilot, and commercial scales without causing toxicity. Promising results were obtained by the combination of batch, fed-batch, and continuous fermentation with gas stripping (Xue et al., 2012). However, gas stripping is accompanied with very low selectivity. Despite advantages such as no fouling and no toxicity, vacuum fermentation and adsorption are also accompanied with low selectivity (Lin et al., 2012). Besides an excess cost of in situ butanol removal, the problems associated with addition of air to the system, energy consumption, and contamination should be considered (Xue et al., 2013; Huang et al., 2014).

In addition to process-based solutions, using solvent tolerant strains of clostridia and other metabolically-engineered bacteria are also among the possible solutions (Abdehagh et al., 2014; Huang et al., 2014). However, using strains of clostridia with a higher tolerance to butanol can improve the $\mathrm{ABE}$ concentration to a minor extent. On the other hand, butanol productivity and yields as well as efficient consumption of a wide verity of sugars present in the substrates by the genetically-engineered microorganisms, including Escherichia coli (Zheng et al., 2009; Huffer et al., 2012), Bacillus subtilis (Kataoka et al., 2011), Saccharomyces cerevisiae (Krivoruchko et al., 2013), and Pseudomonas putida (Ruhl et al., 2009), are still insufficient compared to native strains of $\mathrm{ABE}$ fermenting clostridia.

Increasing butanol concentration and yield, e.g., by elimination of byproducts, increasing the substrate utilization, development of aerotolerant strains have also been investigated by metabolic engineering approaches (Kumar and Gayen, 2011). Inactivation of ethanol, acetone, acetate, and butyrate production can also help to improve the yield of butanol production. However, development of such homo-butanol producers in which more than one by-product is eliminated is still challenging (Papoutsakis, 2008; Kumar and Gayen, 2011; Lütke-Eversloh and Bahl, 2011). Multi-pressure distillation systems and process heat integration as well as membrane separation are suggested to reduce the cost of purification. However, the price for $\mathrm{ABE}$ purification is still much higher than that of ethanol, although the gap is now narrower (Xue et al., 2013).

\section{Concluding remarks}

Butanol, a competitor to most of the other biofuels and petroleum-based products, can be produced biologically via ABE processes. It can be mixed with gasoline at any concentrations and easily transported without the risk of absorbing moisture. Moreover, butanol contains higher energy and has a lower corrosion rate than ethanol. In fact, the ABE process is among the biological processes industrialized long time ago but was stopped for economical reasons 30 years ago. Nevertheless, this process has gained renewed interest recently due to its unique advantages. On the other hand, the $\mathrm{ABE}$ production process is still accompanied with several challenges such as low concentration and difficulty in separation of products, higher feedstock consumption rate (i.e., lower production yield), and sensitivity to substrate composition, inhibitors, and to the presence of oxygen. Different techniques, e.g., pervaporation, vacuum fermentation, gas stripping, perstraction, and adsorption liquid-liquid extraction can help to overcome some of the abovementioned challenges but each of these techniques is accompanied with some drawbacks as well. Strain enhancement to achieve butanol overproduction with higher tolerance is also among the alternative solutions. It is worth mentioning that lignocellulosic wastes seem to be the most promising feedstocks for ABE production in the future. However, the high price of hydrolytic enzymes and the necessity to implement an expensive pretreatment step are still the challenges that need to be overcome. In summary, more research is necessary to revamp the old ABE production processes or the current ethanol production processes to better reflect the requirements of the second generation butanol production in the future.

\section{References}

[1] Abdehagh, N., Tezel F.H., Thibault, J., 2014. Separation techniques in butanol production: Challenges and developments. Biomass Bioenergy. 60, 222-246.

[2] Amiri, H., Karimi, K., 2015. Improvement of acetone, butanol, and ethanol production from woody biomass using organosolv pretreatment. Bioprocess. Biosyst. Eng. 38(10), 1959-1972.
[3] Amiri, H., Karimi, K., Bankar S., Granström T., 2015. Biobutano from Lignocellulosic Wastes. Lignocellulose-Based Bioprod Karimi, K., Springer International Publishing. 1, 289-324.

[4] Amiri, H., Karimi K., Roodpeyma, S., 2010. Production of furan from rice straw by single-phase and biphasic systems. Carbohydr. Res. 345, 2133-2138.

[5] Amiri, H., Karimi K., Zilouei, H., 2014. Organosolv pretreatment of rice straw for efficient acetone, butanol, and ethanol production. Bioresour. Technol. 152, 450-456.

[6] Atsumi, S., Higashide W., Liao, J.C., 2009. Direct photosynthetic recycling of carbon dioxide to isobutyraldehyde. Nature Biotechnol. $27,1177-1180$.

[7] Awang, G.M., Jones G.A., Ingledew, W.M., 1988. The acetonebutanol-ethanol fermentation. Crit. Rev. Microbiol. 15( S1), S33S67.

[8] Bankar, S.B., Survase, S.A., Singhal R.S., Granstrom, T., 2012 Continuous two stage acetone-butanol-ethanol fermentation with integrated solvent removal using Clostridium acetobutylicum B 5313. Bioresour. Technol. 106, 110-116.

[9] Becerra, M., Cerdan M.E., Gonzalez-Siso, M.I., 2015. Biobutano from cheese whey. Microb. Cell Fact. 14, 27.

[10] Boonsombuti, A., Luengnaruemitchai A., Wongkasemjit, S., 2015 Effect of phosphoric acid pretreatment of corncobs on the fermentability of Clostridium beijerinckii TISTR 1461 for biobutanol production. Prep. Biochem. Biotechnol. 45, 173-191.

[11] Boonsombuti, A., Tangmanasakul, K., Nantapipat, J., Komolpis, K., Luengnaruemitchai A., Wongkasemjit, S., 2015. Production of biobutanol from acid pretreated corn cob using Clostridium beijerinckii TISTR 1461: process optimization studies. Prep. Biochem. Biotechnol. (just-accepted).

[12] Breisha, G.Z., 2010. Production of $16 \%$ ethanol from 35\% sucrose. Biomass Bioenerg. 34, 1243-1249.

[13] Cai, D., Zhang, T., Zheng, J., Chang, Z., Wang, Z., Qin P.Y., Tan, T.W., 2013. Biobutanol from sweet sorghum bagasse hydrolysate by a hybrid pervaporation process. Bioresour. Technol. 145, 97-102.

[14] Chen, C., Wang, L., Xiao, G., Liu, Y., Xiao, Z., Deng Q., Yao, P., 2014. Continuous acetone-butanol-ethanol (ABE) fermentation and gas production under slight pressure in a membrane bioreactor. Bioresour. Technol. 163, 6-11.

[15] Chen, C., Xiao, Z., Tang, X., Cui, H., Zhang, J., Li W., Ying, C. 2013. Acetone-butanol-ethanol fermentation in a continuous and closed-circulating fermentation system with PDMS membrane bioreactor. Bioresour. Technol. 128, 246-251.

[16] Chen, Y., Ren, H., Liu, D., Zhao, T., Shi, X., Cheng, H., Zhao, N. Li, Z., Li, B., Niu, H., Zhuang, W., Xie, J., Chen, X., Wu J., Ying, H., 2014. Enhancement of n-butanol production by in situ butano removal using permeating-heating-gas stripping in acetone-butanolethanol fermentation. Bioresour. Technol. 164, 276-284.

[17] Choi, S.J., Lee, J., Jang, Y.S., Park, J.H., Lee S.Y., Kim, I.H., 2012 Effects of nutritional enrichment on the production of acetonebutanol-ethanol (ABE) by Clostridium acetobutylicum. J. Microbiol. 50, 1063-1066

[18] Cooksley, C.M., Zhang, Y., Wang, H., Redl, S., Winzer K., Minton, N.P., 2012. Targeted mutagenesis of the Clostridium acetobutylicum acetone-butanol-ethanol fermentation pathway. Metab. Eng. 14 630-641

[19] Dhamole, P.B., Mane R.G., Feng, H., 2015. Screening of non-Ionic Surfactant for Enhancing Biobutanol Production. App. Biochem. Biotechnol. 1-10.

[20] Ding, J.C., Xu, G.C., Han R.Z., Ni, Y., 2015. Biobutanol production from corn stover hydrolysate pretreated with recycled ionic liquid by Clostridium saccharobutylicum DSM 13864. Bioresour.Technol. In Press.

[21] Dong, H., Tao, W., Dai, Z., Yang, L., Gong, F., Zhang Y., Li, Y., 2012. Biobutanol. Adv. Biochem. Eng./Biotechnol. 128, 85-100.

[22] Durre, P., 2007. Biobutanol: an attractive biofuel. Biotechnol. J. 2, $1525-1534$

[23] Ellis, J.T., Hengge, N.N., Sims R.C., Miller, C.D., 2012. Acetone, butanol, and ethanol production from wastewater algae. Bioresour. Technol. 111, 491-495. 
[24] Ezeji, T., Qureshi N., Blaschek, H.P., 2007. Butanol production from agricultural residues: Impact of degradation products on Clostridium beijerinckii growth and butanol fermentation. Biotechnol. Bioeng. 97, $1460-1469$

[25] Ezeji, T.C., Qureshi N., Blaschek, H.P., 2004. Acetone butanol ethanol (ABE) production from concentrated substrate: reduction in substrate inhibition by fed-batch technique and product inhibition by gas stripping. Appl. Microbiol. Biotechnol. 63, 653-658

[26] Ezeji, T.C., Qureshi N., Blaschek, H.P., 2013. Microbial production of a biofuel (acetone-butanol-ethanol) in a continuous bioreactor: impact of bleed and simultaneous product removal. Bioprocess. Biosyst. Eng. 36, 109-116.

[27] Friedl, A., Qureshi N., Maddox, I.S., 1991. Continuous acetone-butanolethanol (ABE) fermentation using immobilized cells of Clostridium acetobutylicum in a packed bed reactor and integration with product removal by pervaporation. Biotechnol. Bioeng. 38, 518-527.

[28] García, V., Päkkilä, J., Ojamo, H., Muurinen E., Keiski, R.L., 2011. Challenges in biobutanol production: How to improve the efficiency? Renew. Sustain. Energy Rev. 15, 964-980.

[29] Gu, Y., Jiang, Y., Wu, H., Liu, X., Li, Z., Li, J., Xiao, H., Shen, Z., Zhao, J., Yang, Y., Jiang W., Yang, S., 2010. Current status and prospects of biobutanol manufacturing technology. Chin. J. Biotechnol. 26, 914-923.

[30] Han, B., Ujor, V., Lai, L.B., Gopalan V., Ezeji, T.C., 2013. Use of proteomic analysis to elucidate the role of calcium in acetone-butanolethanol fermentation by Clostridium beijerinckii NCIMB 8052. Appl. Environ. Microbiol. 79, 282-293

[31] Hedayatkhah, A., Motamedi, H., Najafzadeh Varzi, H., Ghezelbash, G., Amopour Bahnamiry M., Karimi, K., 2013. Improvement of hydrolysis and fermentation of sugarcane bagasse by soaking in aqueous ammonia and methanolic ammonia. Biosci. Biotechnol., Biochem. 77, 1379-1383.

[32] Huang, H.-J., Ramaswamy S., Liu, Y., 2014. Separation and purification of biobutanol during bioconversion of biomass. Sep. Purif. Technol. $132,513-540$

[33] Huffer, S., Roche, C.M., Blanch H.W., Clark, D.S., 2012. Escherichia coli for biofuel production: bridging the gap from promise to practice. Trends Biotechnol. 30, 538-545.

[34] Jang, Y.-S., Malaviya, A., Cho, C., Lee J., Lee, S.Y., 2012. Butanol production from renewable biomass by clostridia. Bioresour. Technol. $123,653-663$

[35] Jang, Y.S., Malaviya A., Lee, S.Y., 2013. Acetone-butanol-ethanol production with high productivity using Clostridium acetobutylicum BKM19. Biotechnol. Bioeng. 110, 1646-1653.

[36] Jiang, W., Zhao, J., Wang Z., Yang, S.T., 2014. Stable high-titer nbutanol production from sucrose and sugarcane juice by Clostridium acetobutylicum JB200 in repeated batch fermentations. Bioresour. Technol. 163, 172-179.

[37] Jitesh, K., Pangarkar V.G., Niranjan, K., 2000. Pervaporative stripping of acetone, butanol and ethanol to improve $\mathrm{ABE}$ fermentation. Bioseparation. 9, 145-154.

[38] Karimi, K., Brandberg, T., Edebo L., Taherzadeh, M.J., 2005. Fed-batch cultivation of Mucor indicus in dilute-acid lignocellulosic hydrolyzate for ethanol production. Biotechnol. Lett. 27, 1395-1400.

[39] Karimi, K., Pandey, A., 2014. Current and future ABE processes. Biofuel Res. J. 3, 77.

[40] Karimi, K., Shafiei M., Kumar R., 2013. Progress in physical and chemical pretreatment of lignocellulosic biomass, in: Gupta, V.K., Tuohy, M.G. (Eds.), Biofuel Technologies. Springer Berlin Heidelberg, pp. 53-96.

[41] Kataoka, N., Tajima, T., Kato, J., Rachadech W., Vangnai, A.S., 2011. Development of butanol-tolerant Bacillus subtilis strain GRSW2-B1 as a potential bioproduction host. AMB Express. 1, 10.

[42] Khanna, S., Goyal A., Moholkar, V.S., 2013. Production of n-butanol from biodiesel derived crude glycerol using Clostridium pasteurianum immobilized on Amberlite. Fuel. 112, 557-561.

[43] Kharkwal, S., Karimi, I.A., Chang M.V., Lee, D.Y., 2009. Strain improvement and process development for biobutanol production. Recent pat. Biotechnol. 3, 202-210.
[44] Kheyrandish, M., Asadollahi, M.A., Jeihanipour, Doostmohammadi, M., Rismani-Yazdi H., Karimi, K., 2015. Direct production of acetone-butanol-ethanol from waste starch by free and immobilized Clostridium acetobutylicum. Fuel. 142, 129-133.

[45] Komonkiat, I., Cheirsilp, B., 2013. Felled oil palm trunk as a renewable source for biobutanol production by Clostridium spp. Bioresour. Technol. 146, 200-207.

[46] Köpke, M., Dürre P., 2011. Biochemical production of biobutanol, Handbook of Biofuels Production, Luque, R., Campelo J., Clark, J., Woodhead Publishing, pp. 221-257.

[47] Krivoruchko, A., Serrano-Amatriain, C., Chen, Y., Siewers V., Nielsen, J., 2013. Improving biobutanol production in engineered Saccharomyces cerevisiae by manipulation of acetyl-CoA metabolism. J. Ind. Microbiol. Biotechnol. 40, 1051-1056.

[48] Kudahettige-Nilsson, R.L., Helmerius, J., Nilsson, R.T., Sjoblom, M., Hodge D.B., Rova, U., 2015. Biobutanol production by Clostridium acetobutylicum using xylose recovered from birch Kraft black liquor. Bioresour. Technol. 176, 71-79.

[49] Kumar, M. Gayen, K., 2011. Developments in biobutanol production: New insights. Appl. Energy. 88, 1999-2012.

[50] Kumar, M., Goyal, Y., Sarkar A., Gayen, K., 2012. Comparative economic assessment of $\mathrm{ABE}$ fermentation based on cellulosic and non-cellulosic feedstocks. Appl. Energy. 93, 193-204.

[51] Lepiz-Aguilar, L., Rodriguez-Rodriguez, C.E., Arias M.L., Lutz, G. 2013. Acetone-Butanol-Ethanol (ABE) production in fermentation of enzymatically hydrolyzed cassava flour by Clostridium beijerinckii BA101 and solvent separation. J. Microbiol. Biotechnol. 23, 1092-1098

[52] Li, H.G., Luo, W., Gu, Q.Y., Wang, Q., Hu W.J., Yu, X.B., 2013. Acetone, butanol, and ethanol production from cane molasses using Clostridium beijerinckii mutant obtained by combined low-energy ion beam implantation and $\mathrm{N}$-methyl-N-nitro-N-nitrosoguanidine induction. Bioresour. Technol. 137, 254-260.

[53] Li, H.G., Luo, W., Wang Q., Yu, X.B., 2014. Direct fermentation of gelatinized cassava starch to acetone, butanol, and ethanol using Clostridium acetobutylicum mutant obtained by atmospheric and room temperature plasma. Appl. Biochem. Biotechnol. 172, 33303341 .

[54] Li, J., Baral N.R., Jha, A.K., 2014. Acetone-butanol-ethanol fermentation of corn stover by Clostridium species: present status and future perspectives. World J. Microbiol. Biotechnol. 30, 1145 1157

[55] Lin, X., Wu, J., Jin, X., Fan, J., Li, R., Wen, Q., Qian, W., Liu, D. Chen, X., Chen, Y., Xie, J., Bai J., Ying, H., 2012. Selective separation of biobutanol from acetone-butanol-ethanol fermentation broth by means of sorption methodology based on a novel macroporous resin. Biotechnol. Progr. 28, 962-972.

[56] Linden, J.C., A. R. Moreira, A.R., T. G. Lenz T.G., 1986. Acetone and butanol, in: Moo Young, M. (Ed.), Comprehensive biotechnology. Pergamon Press, Oxford, England, pp. 915-931.

[57] Liu, D., Chen, Y., Ding, F.Y., Zhao, T., Wu, J.L., Guo, T., Ren, H.F., Li, B.B., Niu, H.Q., Cao, Z., Lin, X.Q., Xie, J.J., He X.J. Ying, H.J., 2014. Biobutanol production in a Clostridium acetobutylicum biofilm reactor integrated with simultaneous product recovery by adsorption. Biotechnol. Biofuels. 7, 5 .

[58] Liu, X.B., Gu Q.Y., Yu, X.B., 2013. Repetitive domestication to enhance butanol tolerance and production in Clostridium acetobutylicum through artificial simulation of bio-evolution. Bioresour. Technol. 130, 638-643

[59] Loyarkat, S., Cheirsilp B., Umsakul, K., 2013. Direct conversion of sugars and organic acids to biobutanol by non-growing cells of Clostridium spp. incubated in a nitrogen-free medium. Appl. Biochem. Biotechnol. 171, 1726-1738.

[60] Lütke-Eversloh, T., Bahl, H., 2011. Metabolic engineering of Clostridium acetobutylicum: recent advances to improve butano production. Curr. Opin. Biotechnol. 22, 634-647.

[61] Maddox, I.S., 1989. The acetone-butanol-ethanol fermentation: recent progress in technology. Biotechnol. Genet. Eng. Rev. 7, 189. 220. 
[62] Madihah, M.S., Ariff, A.B., Khalil, M.S., Suraini A.A., Karim, M.I., 2001. Anaerobic fermentation of gelatinized sago starch-derived sugars to acetone-1-butanol-ethanol solvent by Clostridium acetobutylicum. Folia microbial. 46, 197-204.

[63] Mariano, A.P., Filho R.M., Ezeji, T.C., 2012. Energy requirements during butanol production and in situ recovery by cyclic vacuum. Renew. Energy. 47, 183-187.

[64] Millat, T., Janssen, H., Bahl, H., Fischer R.J., Wolkenhauer, O., 2013. Integrative modelling of $\mathrm{pH}$-dependent enzyme activity and transcriptomic regulation of the acetone-butanol-ethanol fermentation of Clostridium acetobutylicum in continuous culture. Microbial Biotechnol. 6, 526-539.

[65] Mo, X., Pei, J., Guo, Y., Lin, L., Peng, L., Kou, C., Fan D., Pang, H., 2015. Genome Sequence of Clostridium acetobutylicum GXAS18-1, a Novel Biobutanol Production Strain. Genome Announc. 3(2), e0003315.

[66] Naik, S.N., Goud, V.V., Rout P.K., Dalai, A.K., 2010. Production of first and second generation biofuels: A comprehensive review. Renew. Sustain. Energy Rev. 14, 578-597.

[67] Ni, Y., Sun, Z., 2009. Recent progress on industrial fermentative production of acetone-butanol-ethanol by Clostridium acetobutylicum in China. Appl. Microbiol. Biotechnol. 83, 415-423.

[68] Papoutsakis, E.T., 2008. Engineering solventogenic clostridia. Curr. Opin. Biotechnol. 19, 420-429.

[69] Patakova, P., Linhova, M., Rychtera, M., Paulova L., Melzoch, K., 2013. Novel and neglected issues of acetone-butanol-ethanol (ABE) fermentation by clostridia: Clostridium metabolic diversity, tools for process mapping and continuous fermentation systems. Biotechnol. Adv. 31, 58-67.

[70] Qureshi, N. Maddox, I.S., 2005. Reduction in Butanol Inhibition by Perstraction: Utilization of Concentrated Lactose/Whey Permeate by Clostridium acetobutylicum to Enhance Butanol Fermentation Economics. Food Bioprod. Process. 83, 43-52.

[71] Qureshi, N., Singh, V., Liu, S., Ezeji, T.C., Saha B.C., Cotta, M.A., 2014. Process integration for simultaneous saccharification, fermentation, and recovery (SSFR): Production of butanol from corn stover using Clostridium beijerinckii P260. Bioresour. Technol. 154, 222-228.

[72] Rathore, S., Wan Sia Heng P., Chan, L.W., 2015. Microencapsulation of Clostridium acetobutylicum ATCC 824 spores in gellan gum microspheres for the production of biobutanol. J. Microencapsul. 32, 290-299.

[73] Ruhl, J., Schmid A., Blank, L.M., 2009. Selected Pseudomonas putida strains able to grow in the presence of high butanol concentrations. Appl. Environ. Microbiol. 75, 4653-4656.

[74] Saathoff, A.J., Sarath, G., Chow, E.K., Dien B.S., Tobias, C.M., 2011. Downregulation of cinnamyl-alcohol dehydrogenase in switchgrass by RNA silencing results in enhanced glucose release after cellulase treatment. PloS one. 6, e16416.

[75] Setlhaku, M., Brunberg, S., Villa Edel A., Wichmann, R., 2012. Improvement in the bioreactor specific productivity by coupling continuous reactor with repeated fed-batch reactor for acetone-butanolethanol production. J. Biotechnol. 161, 147-152.

[76] Shafiei, M., Kabir, M.M., Zilouei, H., Sarvari Horvath I., Karimi, K., 2013. Techno-economical study of biogas production improved by steam explosion pretreatment. Bioresour. Technol. 148, 53-60.

[77] Shafiei, M., Karimi K., Taherzadeh, M.J., 2010. Pretreatment of spruce and oak by $\mathrm{N}$-methylmorpholine-N-oxide (NMMO) for efficient conversion of their cellulose to ethanol. Bioresour. Technol. 101, 49144918

[78] Shafiei, M., Karimi K., Taherzadeh, M.J., 2011. Techno-economical study of ethanol and biogas from spruce wood by NMMO-pretreatment and rapid fermentation and digestion. Bioresour. Technol. 102, 78797886.

[79] Shafiei, M., Karimi, K., Zilouei H., Taherzadeh, M.J., 2014. Economic impact of NMMO pretreatment on ethanol and biogas production from pinewood. Biomed Res. Int. 2014, 320254

[80] Shafiei, M., Karimi, K., Zilouei H., Taherzadeh, M.J., 2014. Enhanced ethanol and biogas production from pinewood by NMMO pretreatment and detailed biomass analysis. Biomed Res. Int. 2014, 469378.
[81] Sims, R.E., Mabee, W., Saddler J.N., Taylor, M., 2010. An overview of second generation biofuel technologies. Bioresour. Technol. 101, 1570-1580.

[82] Su, H., Liu, G., He M., Tan, F., 2015. A biorefining process: Sequential, combinational lignocellulose pretreatment procedure for improving biobutanol production from sugarcane bagasse Bioresour. Technol.187, 149-160.

[83] Survase, S.A., van Heiningen A., Granstrom, T., 2012. Continuous bio-catalytic conversion of sugar mixture to acetone-butanolethanol by immobilized Clostridium acetobutylicum DSM 792 Appl. Microbiol. Biotechnol. 93, 2309-2316.

[84] Taherzadeh, M., Karimi, K., 2008. Pretreatment of lignocellulosic wastes to improve ethanol and biogas production: A Review. Int J. Mol. Sci. 9, 1621-1651.

[85] Taherzadeh, M.J., Karimi, k., 2007. Acid-based hydrolysis processes for ethanol from lignocellulosic materials: A review. BioResources. 2, 472-499.

[86] Taherzadeh, M.J., Karimi, K., 2007. Enzymatic-based hydrolysis processes for ethanol from lignocellulosic materials: A review. BioResources. 2, 707-738.

[87] Taherzadeh, M.J., Karimi, k., 2007. Enzyme-based hydrolysis processes for ethanol from lignocellulosic materials: A review. BioResources. 2, 707-738.

[88] Taherzadeh, M.J., Karimi k., 2008. Bioethanol: market an production processes, in: Nag, A. (Ed.), Biofuels refining and Performance. McGraw Hill, New York, pp. 69-106.

[89] Taherzadeh, M.J., Karimi K., 2011. Fermentation inhibitors in ethanol processes and different strategies to reduce their effects, in Ashok, P., Christian, L., Steven C.R., Claude-Gilles D., Biofuels, alternative feedstocks and conversion processes. Amsterdam, Academic Press. pp, 287-311.

[90] Thang, V.H., Kobayashi, G., 2014. A novel process for direct production of acetone-butanol-ethanol from native starches using granular starch hydrolyzing enzyme by Clostridium saccharoperbutylacetonicum N1-4. Appl. Biochem. Biotechnol. $172,1818-1831$

[91] Thompson, A.B., Scholes R.C., Notestein, J.M., 2014. Recovery of dilute aqueous acetone, butanol, and ethanol with immobilized calixarene cavities. ACS Appl. Mater. Interfaces. 6, 289-297.

[92] Tigunova, E.A., Shul'ga S.M., Blium Ia, B., 2013. Alternative type of fuel--biobutanol. Tsitol. Genet. 47, 51-71.

[93] van der Wal, H., Sperber, B.L., Houweling-Tan, B., Bakker, R.R., Brandenburg W., Lopez-Contreras, A.M., 2013. Production of acetone, butanol, and ethanol from biomass of the green seaweed Ulva lactuca. Bioresour. Technol. 128, 431-437.

[94] Wu, Y.D., Xue, C., Chen L.J., Bai, F.W., 2013. Effect of zinc supplementation on acetone-butanol-ethanol fermentation by Clostridium acetobutylicum. J. Biotechnol. 165, 18-21.

[95] Xue, C., Zhao, J., Lu, C., Yang, S.T., Bai F., Tang, I.C., 2012 High-titer n-butanol production by clostridium acetobutylicum JB200 in fed-batch fermentation with intermittent gas stripping. Biotechnol. Bioeng. 109, 2746-2756.

[96] Xue, C., Zhao, X.Q., Liu, C.G., Chen L.J., Bai, F.W., 2013 Prospective and development of butanol as an advanced biofuel. Biotechnol. Adv. 31, 1575-1584

[97] Yadav, S., Rawat, G., Tripathi P., Saxena, R.K., 2014. A novel approach for biobutanol production by Clostridium acetobutylicum using glycerol: A low cost substrate. Renew. Energy. 71, 37-42.

[98] Yazdani, P., Zamani, A., Karimi K., Taherzadeh, M.J., 2015 Characterization of Nizimuddinia zanardini macroalgae biomass composition and its potential for biofuel production. Bioresour. Technol. 176, 196-202

[99] Ye, C., Takigawa, T., Burtovvy, O.S., Langsdorf, L., Jablonski, D., Bell A., Vogt, B.D., 2015. Impact of Nanostructure on Mechanical Properties of Norbornene-based Block Copolymers under Simulated Operating Conditions for Biobutanol Membranes. ACS Appl. Mater. Interfaces. 7, 11765-11774

[100] Yen, H.W., Wang, Y.C., 2013. The enhancement of butanol production by in situ butanol removal using biodiesel extraction in 
[102] Zheng, Y.N., Li, L.Z., Xian, M., Ma, Y.J., Yang, J.M., Xu X., He, D.Z., 2009. Problems with the microbial production of butanol. J. Ind. Microbiol. Biotechnol. 36, 1127-1138. 